\title{
Adopting Lean Six Sigma to AnyLogic Simulation in a Manufacturing Environment
}

\author{
A. Ahmed, J. Page and J. Olsen \\ NSW University, Sydney, NSW, 2052 \\ The School of Mechanical and Manufacturing Engineering, University of New South Wales, \\ Sydney, Australia. \\ Email: A.F.Ahmed@unsw.edu.au.
}

\begin{abstract}
The aim of this paper is to illustrate the use of the Lean Six Sigma (LSS) methodology in a manufacturing environment by adopting the simulation software Anylogic $\AA$. In doing so, we present an innovative approach that implements simulation as a decision-supporting tool in the management of Six Sigma quality improvement projects. We intend to demonstrate how the LSS improvement process, "Define, Measure, Analyse, Improve \& Control" (or DMAIC) can be applied in the Anylogic $\AA$ environment so as to enable us to validate a manufacturing system's existing state and its subsequent improvement. LSS has become the de-facto method for process performance improvement in manufacturing sectors and LSS has been progressively increasing its acceptance in industrial manufacturing that confronts challenges, such as, how to decrease waiting time, maximise capacity, best use resources etc. Determining what alterations and changes to make is not simple and it is not easy to forecast the effect of proposed changes precisely. Coping with complicated systems composed of several interacting components poses the risk of generating $\mathrm{s}$ unacceptable decisions. This paper explains how the simulation program Anylogic $\AA$, with its powerful predictive and visualization capabilities reduces the risk of making undesirable process improvement decisions and assists in ensuring the best possible solutions are found and executed. Consequently, the quality of any process may be enhanced by utilising Lean Six Sigma in an Anylogic Simulation environment and it has the potential to offer a useful approach in term of improving quality and reducing costs. This approach enables evaluation of the performance of the manufacturing process after the proposed and

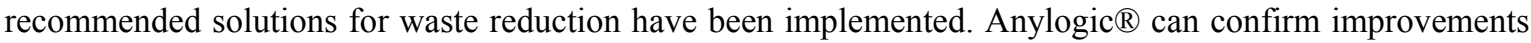
in yield, Defects Per Million Opportunities (DPMO) and six sigma levels.
\end{abstract}

Keywords: $\quad$ Lean Six Sigma (LSS), Simulation, Anylogic $\AA$ 


\section{INTRODUCTION}

Lean Six Sigma (LSS) is a well-known methodology for quality improvement and waste reduction in manufacturing processes. The LSS methodology was firstly developed and implemented by Motorola ${ }^{\circledR}$ in 1985. Motorola was aware that there was a pattern of improvement which could be divided into the five phases of problem solving used by manufacturers, i.e., define, measure, analyse, improve and control (or DMAIC). LSS is a data-driven, restricted approach used to eliminate process complexity, as well as product defects and waste. It aims to reduce the "defects per million opportunities" (DPMO) below 3.4 DPMO. Daryl et al., (2009) proposed a contemporary control chart for attribute data to illustrate the DPBO. The basic value proposition of Six Sigma is that the principles for process improvement, i.e., customer focus, statistical methods, attention to processes and management emphasis on high-return projects, result in continuous improvement with financial gains. Hassan (2013), gave an example involving a welding wire company of a DMAIC process within LSS. Hassan tried to achieve high improvement in quality and productivity using this technique and mentions that the key difficulty was to determine at which stage of the manufacturing process, the methodology implementation should be initiated. Also he stated that LSS methodology is an appropriate approach to be tracked to decrease the waste in manufacturing processes as well as significant costs.

\section{LEAN SIX SIGMA (LSS) MODEL}

Today LSS is emerging as one of the most popular quality/business improvement strategies in both manufacturing and service organizations (Snee, 2010). LSS is a blend of the Six Sigma methodology and the "Lean" approach to enhance the process effectiveness and efficiency (Antony et al., 2003). LSS adopts the define-measure-analyse-improve-control route of Six Sigma through which lean tools are combined with Six Sigma tools (Arcidiacono et al., 2012). The processes to be improved and their measures are identified in the define phase. The present status is assessed in the measure phase and the potential improvement is identified and validated in the analyse phase. The improve phase then addresses the solution(s) in terms of the improved performance level and if appropriate remedial measures are adopted. In the control phase, increasing the achieved gains is addressed by using appropriate statistical, analytical and engineering techniques. Essentially, the statistical tool that is used in the control phase is a control chart. The use of such control charts is an integral part of Six Sigma training. Given the finite amount of training time available, discussions are invariably confined to the basic Shewhart principles for chart construction and application (Goh and Xie, 2003). The other analytical tools used in the control phase are mainly standardization and mistake proofing. It has been found that in most cases, the control phase deals with standardizing the process flow, updating the standard operating procedure (SOP) (Saravanan et al., 2012) and sometimes even constructing the run chart (Rehman et al., 2012). The control chart can be perceived to be more useful when the baseline sigma level of a process is lower while undertaking the journey toward attaining the Six Sigma level of performance. However, after attaining the six-sigma level of performance, a process becomes reliably capable of producing only 3.4 DPMO. Such a high level of performance does not warrant the usage of the conventional attribute control chart, but a modified version that is known as the cumulative count of conforming chart (Goh and Xie, 2003). To decide on the control systems to be used in a particular situation, specific systems for controlling characteristics need to be related to the underlying factors that dominate a process as suggested by Juran and Godfrey (1999).

\section{SIX SIGMA}

With increasing competitive pressure from global markets and technological developments, there has been continual demand for business improvement focused on operations (Meredith and Shafer, 2010). Many improvement initiatives have been implemented to deal with the changing competitive business environment. These include total quality management (TQM), continuous improvement (CI, also known as Kaizen), business process re-engineering, Lean manufacturing and Six Sigma (Meredith and Shafer, 2010). The Six Sigma approach to business improvement has emerged in both the practitioner and academic literature as having a significant impact on competitiveness (McAdam et al., 2005). Six Sigma emphasizes faster processes with lower costs and better quality (Bendic and Tilina, 2010). Benefits derived from Six Sigma implementation include increased company financial performance and improvements in the management system. Six Sigma facilitates more effective problem solutions through the use of data and systematic tools during critical decision-making in organizational change (Wei et al., 2010). Six Sigma emphasizes analyzing processes and organizational development (Bendic and Tilina, 2010). Six Sigma develops a quality culture 
including teamwork, employee empowerment, customer focus, open communication, supplier partnerships, innovation, learning, process approach and organizational loyalty (Davison and Al-Shaghana, 2007). Six Sigma continues to be a key change strategy in many leading organizations (Azis and Osada, 2010, McAdam and Hazlett, 2010). It uses a structured methodology to improve organizational processes that focus on customers and critical-to-quality improvement projects (Parast, 2011). Organizations recognize the need for Lean and Six Sigma methodologies (Snee, 2010). The adoption rate of Six Sigma is increasing (Van der Wiele et al., 2010). A survey conducted by Compdata (Woods, 2010) showed that of 1,100 manufacturing companies surveyed in the USA, 58.6 per cent were using Six Sigma. The results concluded that the deployment of Six Sigma methods remains strong (Woods, 2010).

According to Raisinghani (2005), Six Sigma is a methodology for quality improvement. The concept of Six Sigma was presented in the early 80 's for two reasons: the nature of mass production and the threat of the Japanese products in the American market. At three sigma level, it is known that a working process introduces 2600 DPMO which unsatisfactory in many situations, for example, in the production of printed circuit boards. The execution of Six Sigma is continually done by using the DMAIC approach (Kaushik et.al, 2008). According to Pande et al. (2000), the stages of Six Sigma as follows:

- Define: this stage defines who the customers are, what the customers want, the capabilities of the process, and provides aims for project.

- Measure: measures the quality characteristics which reflects improvement in customer satisfaction and product performance and provides the metrics of data upon which the improvement efforts will be focused.

- Analyse: data collected from pervious steps is fully analysed using analytical tools such as Pareto analysis, process flow diagrams, fish-bone diagrams, statistical process control charts, for identifying necessary design and process modifications for achieving customer satisfaction and performance objectives.

- Improve: allocates resource so that design and process modifications needed for improvement may be implemented.

- Control: processes are monitored using quality management tools and statistical process control charts to ensure performance improvements are maintained.

Chakravorty (2009) stated that the model (DMAIC) indicates a top-down approach as strategic decisions were based on the customer analysis carried out by management. The model, however, calls for planned decisions inferring a bottom up approach where the engineers and indeed operatives are included in making decisions regarding the design of detailed plans to create low level improvement groups and the execution, records, and reconsideration of the plans' implementation.

\section{LEAN}

Lean is a process-improvement methodology, used to deliver products and services better, faster and at a lower cost. Womack and Jones (1996) defined lean as "a way to specify value, line up value-creating actions in the best sequence, conduct those activities without interruption whenever someone requests them, and perform them more and more effectively. In short, lean thinking is lean because it provides a way to do more and more with less and less-less human effort, less human equipment, less time, and less space - while coming closer and closer to providing customers with exactly what they want".

\section{TYPES OF WASTE}

If the operation within a process does not add value to the customer's needs, it is considered wasteful. Lean in manufacturing environment management concentrates on reducing or eliminating waste (Melton, 2005):

1. Over-production: Product made for no potential customer or the development of a product, a process or a manufacturing facility for no potential customer. 
2. Waiting time: While people, equipment or products are waiting, they don't add any value to the customer's product.

3. Transportation: Needless and unnecessary movement of products between several locations. Once products are being moved and not being processed, they don't add value to the customer's product.

4. Over Processing: When a particular process step in the entire manufacturing process does not add value to the product.

5. Inventory: Excessive and unnecessary storage, of for example, products and raw materials.

6. Motion: Unnecessary movement of data, information or the workers who operate the manufacturing facility. While they are in motion, they don't strengthen the product's processing.

7. Defects: Errors that occurs either during the process, requiring re-work or scrapping of the product.

\section{SIX SIGMA ACTIVITIES}

Assarlind et al. (2012) stated that Six Sigma and Lean are deemed as matching each other as well as generally accepted by firms that are attempting for operational and service excellence. Salah et al. (2010) discovered Six Sigma and Lean share a mutual perspective and are used to satisfy the customer. Also, they suggested that Lean and Six Sigma be applied together (Salah et al., 2010) as together, they could lead to an extraordinarily strong methodology (Pepper and Spedding, 2010). Moreover, they mentioned that Six Sigma is a controlled and structured method that improves process performance and attains great levels of quality and lower levels of variability. The Lean system aids companies to accomplish delivery on time at the right quality and quantity. It allows people to understand the product or service and the entire value stream from the customer's perception, to decrease waste and manage production flows (Salah et al., 2010; De Koning and De Mast, 2006). According to Snee (2010), some organisations name it Lean Six Sigma or Six Sigma Lean projects. This combination of Lean and Six Sigma tools depends on the nature of the problem. Also, the combination in terms of improvement and the needs of an organization is shown in Figure below.

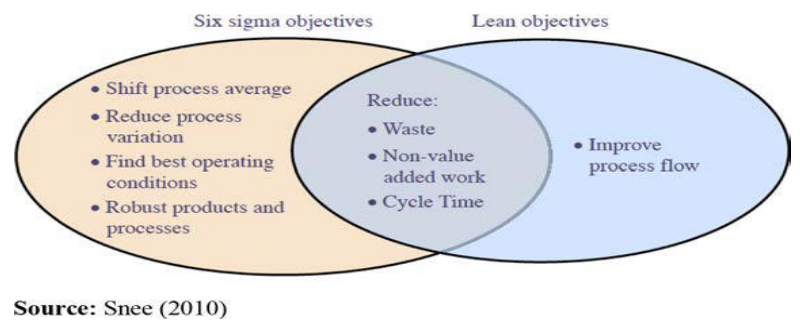

Figure 1. Comparing Lean and Six Sigma

\section{LEAN SIX SIGMA AND SIMULATION}

There is the difficult and variable nature of industrial systems that makes it complex and thus difficult to forecast how a change might influence total performance. So, everyone involved has their own attitude and opinion about how to improve a system. Making informed and intelligent process improvement decisions needs logical abilities which sometimes surpass the capabilities of even the best LSS analysts. Given the complexity of many industrial systems and the increasing demand for better, more affordable services, it is no wonder that determining the optimal system has become a major challenge facing industrial organizations today.

Hahn et al. (2000) argued that simulation is useful in acting in support of the decision analysis processes. This is because of the ability of simulations to assess candidate decisions for difficult business problems and opportunities. They also argue that simulation could be used within the Six Sigma methodology to evaluate and assesses possible alternatives for improvement. Other researchers discuss the integration of Six Sigma and computer simulation to improve outcomes, such as improving a patient's experience in hospital (e.g., Miller \& Ferrin 2005). Ramakrishnan et al. (2008) mention that approaches of LSS have been effective in 
term of improving performance by reducing waste in the design and operational processes. Aft (2001), suggested that "Lean Sigma is a customer focused, well defined, problem solving methodology supported by a handful of powerful statistical tools." Ferrin el al. (2005) mentioned that statistically powerful as these tools are they were diminished by comparison to the interaction and the capability offered by simulation. Additionally, the statistical meticulousness available through valid, verifiable simulation models is an extremely well-matched for Lean Six Sigma. When comparing defects in the Lean Sigma analysis process, simulation is much more capable of predicting Lean Sigma tolerances than other methods. Other "lighter tools" often used in Lean Sigma would not be as "robust" and consequently would not give you the confidence in relation to the solution. In regards to measuring customer satisfaction, simulation is one of the few tools capable of measuring financial indicators, operational indicators and customer satisfaction indicators in the same analysis. Moreover, they state that in measuring critical to quality (CTQ) attributes, sensitivity analysis performed through a valid simulation is an excellent methodology for identifying the most appropriate CTQ impacting the process under review.

\section{LEAN SIX SIGMA AND ANYLOGIC SIMULATION}

XJ Technologies (1992) defined Anylogic $®$ Simulation as a software package designed for simulation tasks. This is an easy to use process that can be programmed either by dragging down is by dragging and dropping elements from palettes as well as by using Java language to program the process from scratch. The software encompasses many kinds of simulation systems, such as discrete-event simulation, process-centric and agent based approaches. They all are attained by using one modelling language and within one development environment. AnyLogic uses Java as its language as it is sufficiently flexible for users to depict the heterogeneity, and complexity of business, economic and social systems. Also, the details are changeable to match many simulation necessities. AnyLogic strengthens the object-oriented model design paradigm which creates potential modular and/or incremental construction of large models. In Anylogic, the agents developed, control their behaviour in relation to their individual built-in state chart. One of the other advantages of AnyLogic is it can run the process in real time and virtual time for most simulations. In real time mode, the mapping of AnyLogic model time to the real time is made, i.e. you specify how many model time units one second takes. It is frequently needed when you want your presentation to appear as in real life. In virtual time mode, the model runs at its maximum speed and no mapping is made between model time units and seconds of astronomical time. This time mode is useful when you need to simulate your model for a long period of time.

\subsection{Agent based model}

The traditional modelling approach deals with a company's personnel, schemes, customer products, and partners as either aggregated averaged quantities or as passive entities or resources in a process. The main feature of any agent based model is that its control system is decentralized (XJ Technologies, 1992). Figure 2 , shows an agent based model of a typical country's population dynamics.

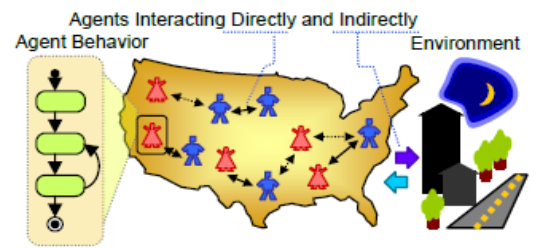

Figure 2. Agent based model structure (Borshchev et.al, 2004).

\subsection{Discrete-event simulation}

Discrete-event simulation (DES) (as shown in the figure 3) is an appropriate tool for analysing the dynamics of discrete processes, such as those found in manufacturing systems. The significant features of discreteevent simulation are its influence on the product's changes, the system's changes and the probability of reducing time. Many different scenarios might be examined in a short time (Banks, 1998). The advantages of DES are well recognized both in industry and the military (e.g., Banks et al., 2003; Banks et al., 2001; 
Law \& Kelton, 2000). They can simulate the behaviour of the entities as soon as an event happens at a distinctive point of time (Hoeger et.al, 1996).

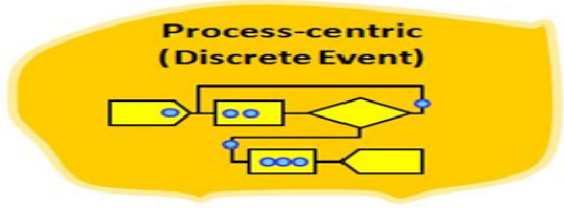

Figure 3. Discrete Event model structure (XJ Technologies, 1992).

The Anylogic simulation environment enables the user to determine the possible consequences of applying many alternatives for improving the overall manufacturing process, without embarking on costly real time investigations. Once this is done, an optimal solution can be selected and implemented for testing in the real world, thus reducing the possibility of damage to the real process and/or the customer's expectations. The combination of Anylogic and LSS could enable the automotive industry, for example, to dodge unexpected and undesired outcomes such as overproduction, dramatic fuel price increases or excessive transportation costs.

In the define stage (D), practitioners have to value the cost savings for each development to be verified and validated. Yet, most of these forecasting costs are made on point estimates of key parameters like raw material cost, customer demand and the cost of capital. By using and applying simulation, the estimates of variability can be built in to generate a more dependable approximation. Moreover, many projects have been proposed where simulation could be used to give assistance to management based on resource restraints and more general aims. Also, in the analysis and improve phases, "design of experiments" is the most common tool used. It provides a base line to predict improvements when modifications are implemented. Furthermore, Anylogic simulation can be used as a control assisting tool when the process is being executed to predict possible problems. Hahn et al., (2000) state that, "Simulation allows one to build a model of a process or system on a computer and to use computer evaluations to assess the impact of alternative strategies". Thus, simulation has traditionally been used to model the building of a product in a factory and to assess both the impact on the time to manufacture and of adding further equipment or personnel. Similarly, simulation can be used to assess business processes, such as the impact on customer waiting time of adding staff to a product telephone "hot line." It can also be used to explore possible political or social changes that if introduced could affect production such as carbon emission controls or statuary recycling.

\section{CONCLUSIONS}

Simulation is a good match with Lean Six Sigma (DMAIC). It is used by many of the world's "best" companies when their answers must be right the first time to avoid significant cost overruns. Moreover, from a Lean Sigma perspective, simulation is an excellent tool capable of providing Lean Sigma quality analytical prowess. Simulation has earned a place in Lean Sigma culture and will continue to develop as a valued tool in delivering customer focused, well defined solutions. It will continue to help companies take small and large steps forward and no steps backward, reducing variation through continuous process improvement while leading teams to improved customer and employee satisfaction.

So, adopting and implementing the five DMAIC phases of LSS within the Anylogic Simulation environment is likely to be a powerful additional tool for a manufacturing organisation. Simulation can assist in the investigation of processes in manufacturing, dealing with some of the complexity and uncertainty which is difficult to determine or analyse using traditional methods. Simulation can make minimal assumptions and can yield a more realistic range of results especially where independent variables are described statistically as a distribution of values. Anylogic and other similar simulation programs are becoming valuable in forecasting future manufacturing performance. The first extension of this investigation will include integrating simulation techniques with LSS. The main impact of integrating simulation with LSS is that it allows the decision-maker to forecast future process performance based on simulated events, which will reduce the risk of an undesirable decision and unforeseen consequences. Many of the traditional tools often produce sub-optimal results or cannot be used at all. For example, if one is designing a new process or product, the system initially does not exist making an investigation of improvements difficult or impossible. Determining the current capability is therefore not an option and so making predictions of future performance is difficult if not impossible without simulation. It is only in recent years that simulation has become sophisticated and rugged enough to fully test innovative solutions before actually implementing them in the business. The refinement of an idea through computerized simulation is the best route to pre- 
implementation testing. It allows us to approach, if not achieve, a high level of accuracy prior to risking significant financial loss. Simulation helps a team focus on the solutions that have the most potential improvement value and further refine those scenarios that will assist efficiency. It brings a higher level of innovation and focuses a team's innovation energy towards the best solutions.

\section{REFERENCES}

Aft, P.E., Larry, S. 2001. Lean Sigma implementation, Champion and green belt training, Course instruction, Centre for Quality Excellence, Southern Polytechnic State University.

Andersson, R., Eriksson, H. and Torstensson, H. (2006), "Similarities and differences between TQM, six sigma and lean", The TQM Magazine, Vol. 18 No. 3, pp. 282-96.

Banks, J.(Ed) (1998), Handbook of Simulation-Principles, Methodology, Advances, Applications, And Practice, Engineering \& Management Press, John Wiley \& Sons, New York, NY.

Borshchev, A., Filippov , A. (2004) From System Dynamics and Discrete Event to Practical Agent Based Modeling: Reasons, Techniques, Tools, The 22nd International Conference of the System Dynamics Society, Oxford, England.

Chakravorty, S., Six Sigma programs: An implementation model, Int. J. Production Economics, 119: 1-16, 2009.

Crosslin, Robert, 1995. Simulation, The key to designing and justifying business reengineering projects, The Electronic College of Process Innovation.

Daryl, S., Beyond Six Sigma - A Control Chart for Tracking Defects per Billion Opportunities (dpbo), International Journal of Industrial Engineering: Theory, Applications and Practice, 16 (3): 227233,2009 .

De Koning, H. and De Mast, J. (2006), "A rational reconstruction of Six Sigma's breakthrough cookbook", International Journal of Quality and Reliability Management, Vol. 23 No. 7, pp. 766-787.

D. M. Ferrin, M. J. Miller, and D. Muthler, "Lean Sigma and simulation, so what's the correlation? V2," Proc. - Winter Simul. Conf., vol. 2005, pp. 2011-2015, 2005.

Hahn, G. J., Doganaksoy, N., \& Hoerl, R. (2000). The evolution of six sigma. Quality Engineering, 12(3), $317-326$.

Mohamed K. Hassan, "Applying Lean Six Sigma for Waste Reduction in a Manufacturing Environment." American Journal of Industrial Engineering 1, no. 2 (2013): 28-35. doi: 10.12691/ajie-1-2-4.

Hammer, M. (2002). 'Process Management and the Future of Six Sigma.' MIT Sloan Management Review, Vol. 43(2), pp. 26-32.

Hoeger H. and Jones J. (1996), Integrating concurrent and conservative distributed discrete event simulators, Simulation for Understanding 67(5), 303-314. Kheir N. A. (1996), System modeling and computer simulation, New York, Marcel Dekker.

Kaushik, P., Khanduja, D., "DM make up water reduction in thermal power plants using Six Sigma DMAIC methodology", Journal of Scientific and Industrial Research, Vol. 67 No.1, pp.36-42, 2008.

Melton, T., The Benefits of Lean Manufacturing What LeanThinking has to Offer the Process Industries, Chemical Engineering Research and Design, 83 (A6): 662-673, 2005.

Miller, M. J., \& Ferrin, D. M. (2005). The application of simulation methodology in a hospital's Six Sigma project. In Simulation Conference, 2005 Proceedings of the Winter (p. 4 pp.). Presented at the Simulation Conference, 2005 Proceedings of the Winter. Retrieved from 10.1109/WSC.2005.1574482.

Raisinghani, M. S., Six Sigma: concepts, tools, and applications, Industrial Management \& Data Systems, 105 (4): 491-505, 2005.

Pande, P.S., Neuman, R.P. and Cavanagh, R.R. (2000), The Six Sigma Way, McGraw-Hill, New York, NY.

Pepper, M.P.J. and Spedding, T.A. (2010), "The evolution of lean Six Sigma", International Journal of Quality and Reliability Management, Vol. 27 No. 2, pp. 138-155.

Ramakrishnan, S., Tsai, P.-F., Drayer, C. M., \& Srihari, K. (2008). Using simulation with Design For Six Sigma in a server manufacturing environment. In Simulation Conference, 2008. WSC 2008. Winter (pp. 1904-1912). Presented at the Simulation Conference, 2008. WSC 2008. Winter. Retrieved from 10.1109/WSC.2008.4736282.

Salah, S., Rahim, A. and Carretero, J.A. (2010), "The integration of Six Sigma and lean management", International Journal of Lean Six Sigma, Vol. 1 No. 3, pp. 249-274.

Snee, R.D. (2010), "Lean Six Sigma - getting better all the time", International Journal of Lean Six Sigma, Vol. 1 No. 1, pp. 9-29.

Thomas, A., Barton, R. and Okafor, C. C., Applying Lean SixSigma in a small engineering company a model for change,Journal of Manufacturing Technology Management, 20 (1): 113-129, 2009.

XJ Technologies Company (1992), available from: www.xjtek.com. 